\title{
Early sexual debut: Voluntary or coerced? Evidence from longitudinal data in South Africa - the Birth to Twenty Plus study
}

\author{
L Richter, ${ }^{1,2}$ BA, BA Hons, PhD; M Mabaso, ${ }^{2}$ BSc, BSc Hons, MSc, PhD; J Ramjith, ${ }^{3}$ BSc, BSc Hons, MSc; \\ S A Norris, ${ }^{1}$ BSc, BSc Hons, BA Hons, PhD \\ ${ }^{1}$ DST-NRF Centre of Excellence in Human Development, University of the Witwatersrand, Johannesburg, South Africa \\ ${ }^{2}$ HIV/AIDS, STIs and TB, Human Sciences Research Council, Durban, South Africa \\ ${ }^{3}$ School of Public Health and Family Medicine, Centre for Infectious Disease Epidemiology and Research, University of \\ Cape Town, South Africa
}

Corresponding author: L Richter (lrichter@hsrc.ac.za)

\begin{abstract}
Background. Early sexual debut, voluntary or coerced, increases risks to sexual and reproductive health. Sexual coercion is increasingly receiving attention as an important public health issue owing to its association with adverse health and social outcomes.

Objective. To describe voluntary and coerced experience at sexual debut.

Methods. A longitudinal perspective among 2216 adolescents (1 149 females, 1067 males) in a birth cohort study in South Africa, analysing data collected on six occasions between 11 and 18 years.

Results. The median age of sexual debut was 16 years for females and 15 for males. Reported coerced sexual debut included children $<11$ years of age. Males reported earlier sexual debut, with both voluntary and coerced sexual experience, than females $(p<0.0001)$. Sexual coercion at early sexual debut among both male and female adolescents occurred mostly through sexual intercourse with older adolescents and partners of the same age.

Conclusion. The identified time periods and age groups need to be targeted for interventions to delay sexual debut and prevent sexual coercion among young people. More research is needed to understand underlying predisposing risk factors for sexual coercion at sexual debut, both early and not early.
\end{abstract}

S Afr Med J 2015;105(4):304-307. DOI:10.7196/SAMJ.8925

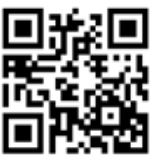

Early sexual debut among young women and men (commonly defined as having had first sexual intercourse at or before age 14 years) is associated with risks to sexual and reproductive health. These include risky sexual behaviours such as multiple partners, sex under the influence of alcohol or drugs, unplanned pregnancy and sexually transmitted infections (STIs), including HIV..$^{[1-3]}$ Early sexual debut not only increases risks to sexual and reproductive health but is also associated with experiences of sexual coercion. ${ }^{[4-6]}$ Sexual coercion has been defined as the act of forcing (or attempting to force) another individual, through violence, threats, verbal insistence, deception, cultural expectations or economic circumstances, to engage in sexual behaviour against his or her will. ${ }^{[4,7]}$

Sexual coercion, which is associated with childhood sexual abuse, is increasingly receiving attention as an important public health issue owing to its association with adverse health and social outcomes. ${ }^{[5-8]}$ Adverse health consequences of sexual coercion among young people have been reported from diverse settings in Latin America, Africa and South Asia; these include self-destructive behaviours such as unprotected sex, non-use of condoms and early non-consensual sexual intercourse. ${ }^{[7-9]}$ In severe cases sexual coercion culminates in prostitution and psychological problems (depression, post-traumatic stress disorder and suicidal ideation), and low self-esteem leading to inability to avoid or refuse unwanted sexual advances and/or negotiate safe sexual behaviours. ${ }^{[9,10]}$ Social outcomes include acceptance of violence, especially towards women, adherence to traditional gender roles such as male dominance, poor educational achievement as a result of withdrawal from school, and inability to build adult partnerships with loss of marriage prospects. ${ }^{[9]}$
In many low- and middle-income countries including South Africa (SA), there is evidence that sexual encounters at a young age are frequently coerced. ${ }^{[4,7]}$ Data from nationally representative cross-sectional surveys indicate that the median age of sexual debut in SA is approximately 16 years for males and 17 years for females. ${ }^{[11-13]}$ Data from four rounds of a prospective population-based survey (conducted from 2003 to 2007) in a rural part of KwaZulu-Natal Province among youths 15 years and older found that the median age at first sexual intercourse was 18.5 and 19.2 years for women and men, respectively. ${ }^{[14]}$ However, studies linking early sexual debut and sexual coercion are scant. ${ }^{[6]}$ This paper describes voluntary or coerced sexual experience at sexual debut from a longitudinal perspective among a large sample of young South Africans participating in the Birth to Twenty Plus cohort.

\section{Methods}

Age at first sexual intercourse was examined in an analysis of data from a prospective longitudinal birth cohort in Soweto, Johannesburg, SA, using information gathered on six occasions from young people between the ages of 11 and 18 years.

\section{The Birth to Twenty cohort (Bt20)}

From 1990 the Bt20 cohort, described in detail elsewhere, ${ }^{[15]}$ enrolled women in their second and third trimesters of pregnancy through public health facilities and interviewed them regarding their health, social history and current circumstances. The children born to these women, together with their families, have been followed up more than 18 times between birth and 23 years of age, with approximately 2300 children and their families remaining in contact with the study. ${ }^{[15]}$ Data for the present study 
came from a sample of 2216 adolescents (1 149 females, 1067 males) between 11 and 18 years of age.

\section{Measures}

Demographic measures used included race and maternal education. Socioeconomic status was determined by a list of household assets and amenities. ${ }^{[16]}$ Sexual behaviour measures (age at first foreplay, oral, anal and/or vaginal intercourse, age and gender of partner, coerced or voluntary) were collected from age 11 years at six subsequent time points (11 - 12 years, 13 years, 14 years, 15 years, 16 years and 17 - 18 years). Self-reported responses were submitted through the method of secret ballot. Questions remained standard and included reports of the first time a young person experienced foreplay, oral sex and sexual intercourse, whether the experience was coerced or not, and characteristics of the first-time partner.

The first-time vaginal or anal intercourse was recorded as the age of sexual debut. Sexual activity prior to 11 years was retrospectively reported. Reports of either foreplay or oral sex were classified as first sexual experience. Tanner staging of pubertal status was determined from adolescent selfassessment using a locally validated scale. ${ }^{[17]}$

\section{Ethics}

Each round of data collection in the Bt20 research programme has ethics approval from the Committee for Research on Human Subjects at the University of the Witwatersrand, Johannesburg (M010556), and counselling services were available to all young people who participated in the study.

\section{Data analysis}

Frequencies and cross-tabulations were calculated to describe the data. Analyses were run separately for males and females, and a two-sample $t$-test was used to assess the level of statistical significance at $p<0.05$. Median age of sexual debut was determined by survival analysis. Data were processed using Stata statistical software (version 12). ${ }^{[18]}$

\section{Results}

Table 1 shows summary statistics for the study participants. Female and male participants were similar in terms of their demographic and socioeconomic characteristics. Girls were ahead of boys in terms of Tanner pubertal self-reports, ${ }^{[17]}$ and more girls than boys reported sexual experience by age 13 .

\section{Age of sexual debut and sexual experience}

The median age of sexual debut was 16 years for females and 15 for males. Fig. 1 shows that irrespective of type of first sexual intercourse, males engaged in sexual intercourse earlier than females $(p<0.0001)$. By 15 years of age, $14.2 \%$ of females and $38.2 \%$ of males had engaged in sexual intercourse. By age 18, $42.9 \%$ of females and $59.5 \%$ of males had engaged in intercourse. There was a dramatic increase in sexual debut among females, and to some extent among males, between the ages of 14 and 17 years. The majority

Table 1. Characteristics of the study participants $(N=2216)$, according to gender

\begin{tabular}{|c|c|c|}
\hline & $\begin{array}{l}\text { Females } \\
(N=1149,52 \%) \\
n(\%)\end{array}$ & $\begin{array}{l}\text { Males } \\
(N=1067,48 \%) \\
n(\%)\end{array}$ \\
\hline \multicolumn{3}{|l|}{ Race } \\
\hline Black & $934(81.3)$ & $866(81.2)$ \\
\hline Coloured & $151(13.1)$ & $137(12.8)$ \\
\hline White & $35(3.0)$ & $35(3.3)$ \\
\hline Asian & $29(2.5)$ & $29(2.7)$ \\
\hline \multicolumn{3}{|c|}{ Socioeconomic status (asset index) } \\
\hline Low & $386(33.6)$ & $383(35.9)$ \\
\hline Middle & $229(19.9)$ & $168(15.7)$ \\
\hline High & $194(16.9)$ & $168(15.7)$ \\
\hline \multicolumn{3}{|l|}{ Maternal education } \\
\hline Primary/less & $132(11.5)$ & $126(11.8)$ \\
\hline Secondary & $820(71.4)$ & $754(70.7)$ \\
\hline Post-school training & $99(8.6)$ & $98(9.2)$ \\
\hline \multicolumn{3}{|c|}{ Pubertal stage (Tanner self-rating) ${ }^{[17]}$ at age 13 years } \\
\hline Prepubertal & $60(5.2)$ & $177(16.6)$ \\
\hline Early puberty & $636(55.4)$ & $628(58.9)$ \\
\hline Mid puberty & $261(22.7)$ & $81(7.6)$ \\
\hline Late puberty & $29(2.5)$ & $81(7.6)$ \\
\hline \multicolumn{3}{|c|}{ Sexual experience by age 13 years } \\
\hline Foreplay or oral sex & $922(80.2)$ & $787(73.8)$ \\
\hline
\end{tabular}

Table 2. Adolescent males and females who had not and those who had engaged in sexual intercourse and their first sexual experience (voluntary or coerced) by the end of the 18-year wave

\begin{tabular}{|c|c|c|c|c|c|c|c|c|}
\hline \multirow[b]{2}{*}{ Age (years) } & \multicolumn{4}{|c|}{ Females $1149(51.9 \%), n(\%)$} & \multicolumn{4}{|c|}{ Males $1067(48.1 \%), n(\%)$} \\
\hline & $\begin{array}{l}\text { Not yet engaged } \\
\text { in sex }\end{array}$ & $\begin{array}{l}\text { Engaged } \\
\text { in sex }\end{array}$ & Voluntary & Coerced & $\begin{array}{l}\text { Not yet engaged } \\
\text { in sex }\end{array}$ & $\begin{array}{l}\text { Engaged } \\
\text { in sex }\end{array}$ & Voluntary & Coerced \\
\hline$\leq 12$ & $1136(98.9)$ & $13(1.2)$ & $3(0.3)$ & $10(0.9)$ & $958(89.8)$ & $109(10.2)$ & $66(6.2)$ & $43(4.0)$ \\
\hline$\leq 13$ & $1118(98.1)$ & $22(1.9)$ & $6(0.5)$ & $16(1.4)$ & $887(83.8)$ & $171(16.2)$ & $114(10.8)$ & $57(5.4)$ \\
\hline$\leq 14$ & $1075(94.9)$ & $58(5.1)$ & $30(2.6)$ & $28(2.5)$ & $772(73.6)$ & $277(26.4)$ & $197(18.8)$ & $80(7.6)$ \\
\hline$\leq 15$ & $963(85.8)$ & $160(14.2)$ & $107(9.5)$ & $53(4.7)$ & $641(61.8)$ & $396(38.2)$ & $285(27.5)$ & $111(10.7)$ \\
\hline$\leq 16$ & $815(73.4)$ & $296(26.4)$ & $222(20.0)$ & $74(6.6)$ & $529(51.7)$ & $495(48.3)$ & $362(35.3)$ & $133(13.0)$ \\
\hline$\leq 17$ & $672(61.5)$ & $420(38.5)$ & $331(30.3)$ & $89(8.2)$ & $447(44.3)$ & $561(55.7)$ & $415(41.2)$ & $146(14.5)$ \\
\hline$\leq 18$ & $585(57.1)$ & 440 (42.9) & $349(34.0)$ & $91(8.9)$ & $387(40.5)$ & $568(59.5)$ & 419 (43.9) & $149(15.6)$ \\
\hline
\end{tabular}


of females reported experiencing their first sexual intercourse between 15 and 17 years of age, peaking at 16 . There was a less dramatic increase among males, with the majority experiencing sexual debut at a younger age, 14 - 16 years, peaking at age 16 .

Table 2 shows the cumulative frequency distribution for adolescent males and females (and both groups combined) who had, and those who had not, engaged in sexual intercourse by the end of the 18-year wave, and whether their first sexual experience was coerced. Reported sexual intercourse before age 12 was ten times higher among boys than girls. However, more females, and especially those younger than 14 years, reported their first sexual intercourse as coerced.

Table 3 shows reported age differences between young people and their first sexual partners. Except for two girls and two boys, all reported partners tended to be within a 4-year age difference. Irrespective of coerced or voluntary sexual debut, significantly $(p<0.05)$ more males had partners with no age difference or who were 1 - 4 years younger than themselves, and a significantly higher proportion of females had partners who were 1 year or more older.

\section{Discussion}

Nearly half of all the participants followed prospectively had not engaged in sexual intercourse by the age of 18 years. Males engaged in sexual intercourse earlier than females, irrespective of whether the first sexual experience was voluntary or coerced. Furthermore, more males than females reported both voluntary and coerced sexual debut across all ages. The results draw attention to high rates of sexual coercion of young men, a phenomenon little studied in sub-Saharan Africa. ${ }^{[19]}$ First sexual intercourse was reported at a very young age by some young people, especially girls younger than 13 years.

Rates of childhood sexual abuse are reported to be high in SA, with high levels of penetrative sexual abuse before age 12 , especially among girls. ${ }^{[20]}$ There is evidence that girls experiencing sexual abuse are more likely to engage in riskier sexual behaviours, including early sexual debut, than their peers. ${ }^{[4,20]}$ Sex involving children younger than 16 years of age is illegal in SA, and children reporting oral sex or sexual intercourse before this age were referred to the study counsellor, who made further referrals.

Very few studies have looked at the sexual coercion experiences of adolescents in subSaharan Africa at their sexual debut. ${ }^{[7]}$ Those that have indicate that coercion is common, affecting between $15 \%$ and $38 \%$ of adolescent girls. ${ }^{[21]}$ In our study, sexual coercion tended to involve older sexual partners, although among older girls, only $9 \%$ of coerced sex was reported to have taken place with a partner 4 years or more older. In another SA study, sexual coercion was associated with significantly older partners. ${ }^{[4]}$ However, our data also suggest that sexual coercion between same-aged groups is prevalent in SA, especially among those aged 15 - 17 years. These observations are in line with the findings of previous studies in the country. ${ }^{[12-14]}$ Interventions to counter coerced sexual intercourse therefore need to target both adolescents and young adults.

This is one of very few prospective studies of sexual debut, and has collected data on both voluntary and coerced first sexual experience; it is the only study in SA that has collected prospective data from the preteen years. While the data are limited by the unknown validity of self-reports of sexual behaviour, every effort was made to enhance the validity of reported sexual behaviour through use of the method of secret ballot. Nonetheless, topic sensitivity and social desirability effects could have contributed to a well-known tendency towards female underreporting and male over-reporting of sexual experiences. ${ }^{[22]}$ The objective of this study was mainly descriptive in nature. A more detailed analysis of the determinants of coercion at first sexual experience will be able to throw more light on the underlying risk factors.

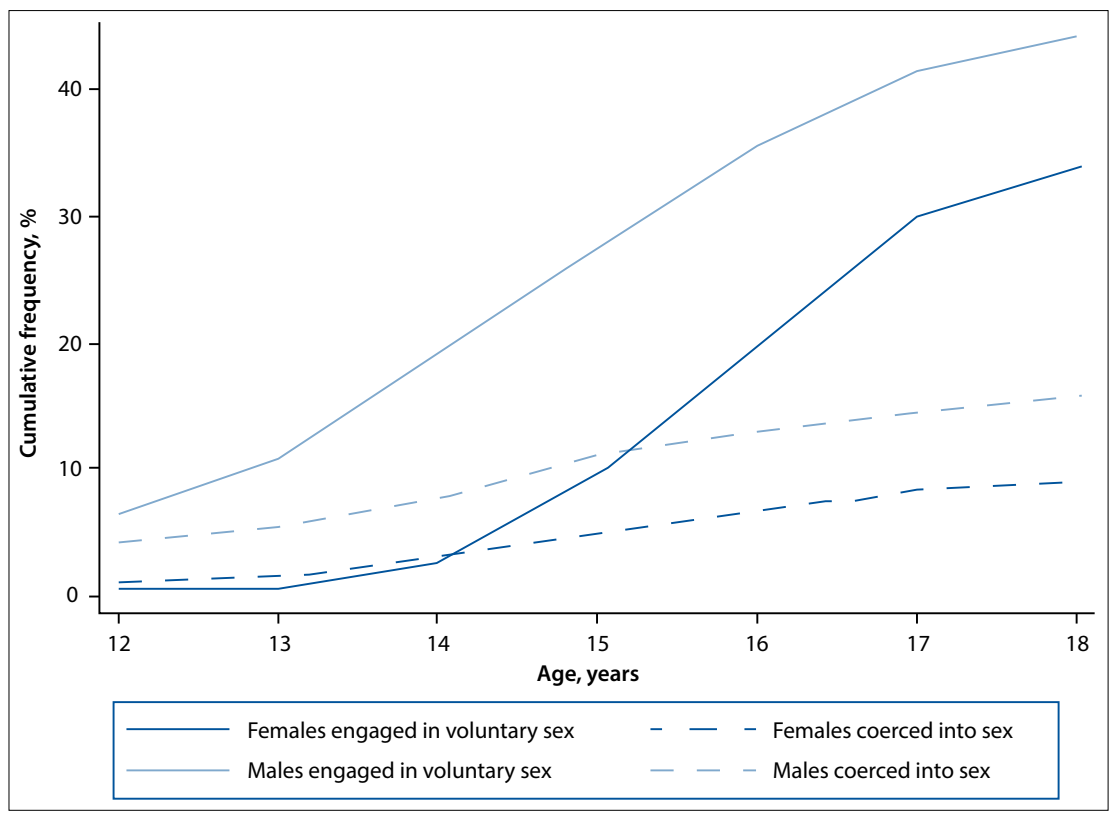

Fig. 1. Sexual debut for males and females by age from the first retrospective report of sexual intercourse, starting before 12 years of age.

Table 3. Partner age differences and sexual experience (voluntary or coerced) at first sexual intercourse by gender

\begin{tabular}{|c|c|c|c|c|}
\hline \multirow[b]{2}{*}{ Age difference } & \multicolumn{2}{|c|}{ Voluntary } & \multicolumn{2}{|c|}{ Coerced } \\
\hline & $\begin{array}{l}\text { Females }(N=348) \\
n(\%)\end{array}$ & $\begin{array}{l}\text { Males }(N=419) \\
n(\%)\end{array}$ & $\begin{array}{l}\text { Females }(N=91) \\
n(\%)\end{array}$ & $\begin{array}{l}\text { Males }(N=149) \\
n(\%)\end{array}$ \\
\hline Partner $\geq 5$ years younger & $1(0.3)$ & $2(0.5)$ & $0(0 \%)$ & $0(\%)$ \\
\hline Partner 1 - 4 years younger & $3(0.9)$ & $115(27.4)^{*}$ & $1(1.1)$ & $45(30.2)^{*}$ \\
\hline Partner same age & $42(12.1)$ & $143(34.1)^{*}$ & $15(16.5)$ & $53(35.6)^{*}$ \\
\hline Partner 1 - 4 years older & $239(68.7)^{*}$ & $115(27.4)$ & $55(60.4)^{*}$ & $30(20.1)$ \\
\hline Partner $\geq 5$ years older & $45(12.9)^{*}$ & $2(0.5)$ & $10(11.0)^{\star}$ & $2(1.3)$ \\
\hline
\end{tabular}




\section{Conclusion}

This study found that coerced sexual debut among young adolescents occurred mostly through sexual intercourse with peers, older adolescents and young adults, rather than with older adults. These time periods and age groups therefore also need to be targeted for interventions to delay sexual debut and prevent sexual coercion. Targeted interventions aimed at delaying sexual debut and sexual coercion will help to prevent adolescent sexual risk behaviour, unwanted pregnancy and STIs, including HIV. More research is needed on the predisposing risk factors for sexual coercion as it relates to early sexual debut among youth, in order to inform existing and new prevention programmes targeted at intervening during childhood and adolescence.

Acknowledgements. We are grateful for funding received from the Wellcome Trust, the University of the Witwatersrand, the South African Medical Research Council and the South African Human Sciences Research Council. We acknowledge the input of Nuala McGrath, Clare Schur and Rashmika Singh to an earlier analysis plan.

\section{References}

1. Harrison A, Cleland J, Gouws E, Frohlich J. Early sexual debut among young men in rural South Africa: Heightened vulnerability to sexual risk? Sex Transm Dis 2005;81(3);259-261. [http://dx.doi. org/10.1136/sti.2004.011486]

2. Pettifor A, O'Brien K, MacPhail C, Miller W, Rees H. Early coital debut and associated HIV risk factors among young women and men in Sout

3. Stöckl $\mathrm{H}, \mathrm{Kalra} \mathrm{N}$ Jacobi $I$ Watts $\mathrm{C}$. Is early sexual debut a risk factor for HIV infection among women 3. Stockl H, Kalra N, Jacobi J, Watts C. Is early sexual debut a risk factor for HIV infection among women
in Sub-Saharan Africa? A systematic review. Am J Reprod Immunol 2013;69(Suppl 1):27-40. [http:// dx.doi.org/10.1111/aji.12043]

4. Jewkes R, Abrahams N. The epidemiology of rape and sexual coercion in South Africa: An overview. Soc Sci Med 2002;55(7):1231-1244. [http://dx.doi.org/10.1016/S0277-9536(01)00242-8]

5. Erulkar AS. The experience of sexual coercion among young people in Kenya. Int Fam Plan Perspect 2004;30(4):182-189. [http://dx.doi.org/10.1363/3018204]
6. Maharaj P, Munthree C. Coerced first sexual intercourse and selected reproductive health outcomes among young women in KwaZulu-Natal, South Africa. J Biosoc Sci 2007;39(2):231-244. [http://dx.doi. rg/10.1017/S0021932006001325]

7. Koenig M, Lutalo T, Zhao F, et al. Coercive sex in rural Uganda: Prevalence and associated risk factors. Soc Sci Med 2004;58(4):787-798. [http://dx.doi.org/10.1016/S0277-9536(03)00244-2]

8. Noell J, Rohde P, Seeley J, Ochs L. Childhood sexual abuse, adolescent sexual coercion and sexually transmitted infection acquisition among homeless female adolescents. Child Abuse and Neglect 2001;25(1):137-148. [http://dx.doi.org/10.1016/S0145-2134(00)00223-4]

9. Jejeebhoy SJ, Bott S. Non-consensual Sexual Experiences of Young People: A Review of the Evidence from Developing Countries. South and East Asia Regional Working Paper No. 16. New Delhi: India Population Council, 2003.

10. Agardh A, Tumwine G, Asamoah BO, Cantor-Graae E. The invisible suffering: Sexual coercion, interpersonal violence, and mental health - a cross-sectional study among university students in southwestern Uganda. PLoS One 2012;7(12):e51424. [http://dx.doi.org/10.1371/journal.pone.0051424]

11. Pettifor AE, Rees HV, Kleinscmidt I, et al. Young people's sexual health in South Africa: HIV prevalence and sexual behaviours from a nationally representative household survey. AIDS 2005:19(14):15251534. [http://dx.doi.org/10.1097/01.aids.0000183129.16830.06]

12. Shisana O, Rehle T, Simbayi L, et al. South African National HIV Prevalence, HIV Incidence, Behaviour and Communication Survey. Cape Town, HSRC Press, 2005.

13. Zuma K, Setswe G, Ketye T, Mzolo T, Rehle T, Mbelle N. Age at sexual debut: A determinant of multiple partnerships among South African youth. Afr J Reprod Health 2010;14(2):47-54.

14. McGrath N, Nyirenda M, Hosegood V, Newell M-L. Age of first sex in rural South Africa. Sex Transm Dis 2009;85(Suppl 1):S49-S55. [http://dx.doi.org/10.1136/sti.2008.033324]

15. Richter L, Norris S, Pettifor J, Yach D, Cameron, N. Mandela's children: The 1990 Birth to Twenty study in South Africa. Int J Epidemiol 2007;36(6):504-511. [http://dx.doi.org/10.1093/ije/dym016]

16. Filmer D, Scott K. Assessing Asset Indices. Washington, DC: World Bank, 2008. [http://dx.doi. org/10.1596/1813-9450-4605]

17. Norris S, Richter L. Usefulness and reliability of Tanner pubertal self-rating to urban black adolescents in South Africa. J Res Adolesc 2005;15(4):609-624. [http://dx.doi.org/10.1111/j.15327795.2005.00113.x]

18. StataCorp. Stata Statistical Software: Release 12. College Station, TX: StataCorp LP, 2011.

19. Richter L, Komárek A, Desmond C, et al. Reported physical and sexual abuse in childhood and adult HIV risk behaviour in three African countries: Findings from Project Accept (HPTN-043). AIDS Behav 2014;18(2):381-389. [http://dx.doi.org/ 10.1007/s10461-013-0439-7]

20. Jewkes R. Non-consensual sex among South African youth: Prevalence of coerced sex and discourses of control and desire. In: Jejeebhoy S, Shah I, Thapa S, eds. Sex without Consent: Young People in Developing Countries. New York: Zed Press, 2005.

21. Moore AM, Awusabo-Asare K, Nyovani Madise N, John-Langba J, Kumi-Kyereme A. Coerced first sex among adolescent girls in sub-Saharan Africa: Prevalence and context. Afr J Reprod Health 2007;11(3):62-82. [http://dx.doi.org/10.2307/25549732]

22. Nnko S, Boerma T, Urassa M, Mwaluko J, Zaba B. Secretive females or swaggering males? An assessment of the quality of sexual partnership reporting in rural Tanzania. Soc Sci Med 2004;59(2):299-310. [http://dx.doi.org/10.1016/j.socscimed.2003.10.031]

Accepted 13 February 2015. 